\title{
The role of feedback in the process of learning English as a foreign language
}

Anna HERRA

Ateneum-Szkoła Wyższa w Gdańsku

Anna KULIŃSKA ${ }^{1}$

Ateneum-Szkoła Wyższa w Gdańsku

\section{Summary}

The aim of the paper is to answer the question of what is the role of Feedback in the process of learning English as a foreign language. Feedback is an important element of student-teacher interaction in the classroom. Even experienced teachers admit that it is beneficial to put oneself in the student's position in order to understand their individual needs, and hence adjust the instruction, assessment and feedback moves to aid language acquisition. Since errors are an unavoidable part of the learning process and teachers feel compelled to address students' spoken errors, it seems significant to consider how the learners perceive the feedback they receive.

Keywords: education, foreign language teaching, feedback, English language

\section{Introduction}

Every once in a while a teacher comes to the realization that despite all the effort and countless correction, students still make the same errors. Sometimes it is because the expectations towards the learners are too high, on other occasions it is because students lack interest to advance in their language development, and sporadically there is a mismatch between what teachers communicate and what students receive and process. Feedback is an important element of studentteacher interaction in the classroom. Even experienced teachers admit that it is beneficial to put oneself in the student's position in order to understand their individual needs, and hence adjust the instruction, assessment and feedback moves to aid language acquisition. Seeing that errors are an unavoidable part of the learning process and that teachers feel compelled to address students' spoken errors, it seems significant to consider how the learners perceive the feedback they receive.

All responsible EFL practitioners tries their best to meet his students' language needs and thus enhance their performance. In so doing, they employ

https://orcid.org/0000-0001-7793-4563. 
different techniques and strategies to reach this goal. All this can be effectively done provided that he receives some responses, i.e. feedback, from his learners. As Wang (2006: 42) states, 'feedback is the information about current performance that can be used to improve future performance.' Feedback plays a crucial role in any educational process since it can significantly improve both learner's and teacher's performance and indicate some key aspects of their performance, which can be improved. Dignen (2014) argues that feedback is the most important communication skill, both outside and inside the classroom.

Making errors is a natural and unavoidable part of language learning, and it is a teacher's responsibility to give feedback in such a way which helps the learning process and aids language acquisition. That being said, both teachers and SLA theorists are deeply concerned with the issue of corrective feedback and its potentially beneficial role in language learning.

\section{Research on feedback in the field of language teaching}

In order to understand the importance of students' attitude towards correction in the English classroom, it is essential to explain why corrective feedback plays an important role in the process of second language acquisition and why giving feedback in general is regarded as one of the key elements in the process of learning. This chapter aims to clarify the term 'corrective feedback' and review different theoretical approaches to the giving of feedback. It also offers an overview of some research results concerning the efficacy of corrective feedback in SLA so that there is no doubt left as to its facilitative role in the process of language acquisition.

Feedback is a notion frequently used in the field of language teaching. As a form of shared or exchanged information, it might occur between teachers, students, or it might even be provided by third parties, such as parents or higher authorities, for the purpose of school or class self-evaluation. Most often, however, it is associated with teachers providing assessment to their students. Ur (1996: 242) defines feedback as "information that is given to the learner about his or her performance of a learning task, usually with the objective of improving this performance". What is more, because of its complexity, feedback is a notion subjected by researchers to various typologies; thus they differentiate between oral and written feedback, positive or negative feedback, as well as immediate vs. delayed feedback, or explicit vs. implicit feedback. Some distinctions are more elusive, for example evaluative (judgmental) vs. descriptive feedback (with reference to achievement or competence) is also mentioned in the literature (Hargreaves, E., 2000: 21). 
Corrective feedback is most commonly understood as responding to learner's utterances containing an error during practice. For the purpose of this paper, the term corrective feedback can be defined as "any reaction of the teacher which clearly transforms, disapprovingly refers to, or demands improvement of the learner utterance" (Chaudron 1977: 31). According to Ellis (2009: 3), corrective feedback is an example of negative feedback because, as opposed to positive feedback, it is a reaction to a linguistic error and not an appraisal of a correct utterance. Ellis also states that it is important to recognize that the teacher's responses can take different forms. Feedback move, he says: "can consist of (1) an indication that an error has been committed, (2) provision of the correct target form (3) metalinguistic information about the nature of the error or (4) any combination of the above." (2009: 4).

Providing feedback to learners in the classroom has long been considered by teachers as an essential element in the process of acquiring various skills and such conviction definitely applies to both first and second language acquisition. There are, however, disagreements among theorists regarding the most desirable form of the feedback given and the efficacy of corrective feedback, when discussing second language acquisition. The theoretical debate over the value of corrective feedback has spawned a great deal of empirical research. Early studies were not favorable to the idea. For example, in his article, Kim (2004: 5) cites the results of studies conducted by Chun (1982), which revealed that only $8.9 \%$ of incorrect utterances met with corrective feedback. Likewise, Kim also mentions that Chauldron (1988), in his review of various studies, discovered that "feedback was provided erratically and often went unnoticed by students" (2004:5).

Recently, however, attitudes towards error correction have changed considerably. A vast amount of research conducted has proved that corrective feedback used in the classroom can be beneficial. It should be noted, however, that although the results advocate the usage of feedback, it remains unclear which type of feedback produces the best results. A study conducted by Lightbown and Spada (1990) was designed to measure the ability to form English noun phrases correctly by young native speakers of French. The researchers concluded that in communicative language teaching, an instruction focused on form led to increased linguistic accuracy (1990: 443). Likewise, Carrol and Swain (1992) investigated how English native speakers benefit from feedback when learning French. They discovered that feedback helped to learn and memorize new items, although learners not always were able to induce morphological generalizations (1992: 186). Furthermore, Oliver (1995) contradicted Chun's results when he 
discovered that during a conversation, native speaker children provided corrective feedback to non-native speakers in 61\% of cases (1995: 473).

Lyster and Ranta used the three-phase model of skill learning to interpret the results of their study from 1997 in which they investigated different feedback techniques used with primary French-Canadian learners of English. They noticed that in the declarative knowledge phase, which they called the awareness phase, feedback helps to "draw learners' attention to the target feature" (Lyster \& Ranta 2007: 150). In the second and third phase, learners already equipped with the knowledge, are exposed to various practice opportunities. Consequently, in order to achieve the stage of proceduralization and automatization, they receive plenty of feedback while performing cooperative learning activities. Their main conclusion of the study was that despite the fact that recasts were the most frequently used form of feedback by teachers, it was more beneficial for students when teachers used rather less direct forms of correction which prompt learners to self-repair (Lyster \& Ranta 2007: 153).

It should also be mentioned that Norris and Ortega (2000) conducted a meta-analysis of research on the effectiveness of instruction and provided more encouraging evidence regarding feedback. They believe classroom instruction serves as the main source of input for learners and it is effective regardless of it being explicit or implicit or a mixture of both. The findings of the study revealed that the groups receiving instruction outperformed the control groups (2000: 500). Teachers definitely need further guidance on how best to provide feedback but they should not hesitate to use it in the classroom. A considerable amount of research suggests that learners ought to be exposed to correction as it is beneficial and, if done properly, can aid acquisition.

With the growing popularity of communicative approaches and a considerable body of research on the efficacy of corrective feedback, a number of different feedback types have been identified. The most wildly used and cited is the taxonomy based on the data analysis of classroom interaction in French immersion programs conducted by Lyster and Ranta (1997: 40). They identified six different feedback moves: explicit correction, recast, elicitation, clarification request, metalinguistic clues and repetition (Table 1). In their view, translation technique initially was treated as a form of recast, it does, however, differ significantly because of the use of non-target language, and therefore, it is discussed independently here. Moreover, Elis (2009: 8) also recognizes paralinguistic signals as a separate feedback move. 
Table 1. Types and examples of feedback

\begin{tabular}{|c|c|}
\hline Type of feedback & Examples \\
\hline explicit correction & $\begin{array}{l}\text { S: I didn't go to school tomorrow. I was sick. } \\
\text { T: No, not tomorrow. You should say: yesterday. }\end{array}$ \\
\hline recast & $\begin{array}{l}\text { T: When did you buy the books? } \\
\text { S: I buy the books yesterday. } \\
\text { T: You bought the books yesterday. }\end{array}$ \\
\hline elicitation & $\begin{array}{l}\text { S: After work, she go shopping. } \\
\text { T: After work she ...... (rising intonation to signal that the student } \\
\text { should finish the sentence) } \\
\text { S: After work, she goes shopping. }\end{array}$ \\
\hline $\begin{array}{l}\text { clarification } \\
\text { request }\end{array}$ & $\begin{array}{l}\text { S: Can I have the toilet, please? } \\
\text { T: I'm sorry? or I don't understand? } \\
\text { S: Can I go to the toilet, please? }\end{array}$ \\
\hline metalinguistic & $\begin{array}{l}\mathrm{S}: \text { After work he went to home. } \\
\mathrm{T}: \text { Do we say 'go to home'?" } \\
\mathrm{S}: \text { After work he went home. }\end{array}$ \\
\hline repetition & $\begin{array}{l}\text { T: How old are you? } \\
\text { S: I have } 12 \text { years old } \\
\text { T: } \underline{H A V E} ? \underline{\text { I HAVE } 12 \text { years old?! }} \\
\text { S: I } \underline{\text { am } 12} \text { years old }\end{array}$ \\
\hline translation & $\begin{array}{l}\text { S: I am interesting in sports. } \\
\text { T: Are you sure you wanted to say: Jestem interesujący w sportach? } \\
\text { S: I am interested in sports. }\end{array}$ \\
\hline non-verbal clues & $\begin{array}{l}\text { S: I have three book. } \\
\text { T: ... says nothing but makes a facial expression which signals } \\
\text { the ill-formed utterance or counts, using fingers. } \\
\text { S: I have three books. }\end{array}$ \\
\hline
\end{tabular}


It is a common belief among teachers that not every mistake needs correction or at least not an immediate one. Depending on the type of communicative task, the teacher might decide to ignore the error in order not to interrupt the flow of conversation. In cases where a strong emphasis is placed on the meaning and not on the grammatical or phonological accuracy providing immediate feedback also seems less imperative. What is more, for the correction to be successful, several conditions must be met; for instance, the learner needs to realize that his utterance was ill-formed.

Ellis (2009: 4) uses the term corrective feedback episodes and suggests that each episode is comprised "a trigger, a feedback move, and (optionally) uptake". He further emphasizes that those episodes can be either simple- involving one strategy or more complex- involving a whole series of moves. Similarly, Lyster and Ranta (1997) point to error treatment sequence model which comprises teacher and student turns in the order of (1) learner error (2) teacher feedback (3) learner uptake with or without repair (Panova \& Lyster, 2002: 581). One of the key elements of the process occurring while correcting is the choice of feedback type that the teacher makes. To give a better understanding of different feedback moves, researchers developed various taxonomies of correction types. Perhaps, the most common division of corrective feedback techniques is the one which places feedback moves on an implicit-explicit spectrum and, though, the degree to which correction is implicit or explicit varies, it can be classified in the following manner.

Table 2: A taxonomy of CF strategies (Ellis 2009: 8)

\begin{tabular}{|l|l|l|}
\hline Feedback move & \multicolumn{1}{|c|}{ Implicit } & \multicolumn{1}{|c|}{ Explicit } \\
\hline Input-providing & Recast & Explicit correction \\
\cline { 2 - 3 } Output-prompting & $\begin{array}{l}\text { Repetition } \\
\text { Clarification request }\end{array}$ & $\begin{array}{l}\text { Metalinguistic explanation } \\
\text { Elicitation } \\
\text { Paralinguistic signal }\end{array}$ \\
\hline
\end{tabular}

It should be noted that different feedback strategies (both implicit and explicit) are frequently used together for a greater effect, a good example being repetition and a thumbs down signal used together to accentuate the error. Moreover, when a student finds it difficult to recognize the ill-formed part of his utterance a sequence of corrective moves may fallow, starting with more implicit 
techniques, and moving on to those more explicit ones. Also, even after student's self-repair, the teacher may continue the topic of problematic structures by giving detailed metalinguistic explanation.

Another useful classification was introduced by Lyster and Ranta when they were discussing the role of feedback in "The Awareness-Practice-Feedback sequence" for developing instructional activities (Lyster \& Ranta 2007: 152). They divided feedback moves into two different categories: reformulations (inputproviding feedback) and prompts (also called negotiation of form). They listed recasts and explicit feedback as examples of reformulation and the outputprompting moves they classified as prompts. The idea behind the division was that all techniques identified as prompts "withhold correct forms and instead provide clues to prompt students to retrieve correct forms from what they already know" (ibid.). Therefore, feedback moves such as elicitation, clarification request, metalinguistic clues and repetition enable the teacher to push students to selfrepair in a variety of ways, whereas recasts and explicit feedback provide the answers for students.

The purpose of using corrective feedback in the classroom is not to show learner's deficiency in language accuracy, but to help him avoid mistakes in the future. On a smaller scale, the teacher's intention is to inform the student on the correct form or to elicit the correct answer from them. Sheer exposure to implicit or explicit feedback initiates the process but it is the final result, referred to in the literature as uptake, that constitutes an effective corrective move. Lyster and Ranta (1997: 40) define uptake as "student's utterance that immediately follows the teacher's feedback and that constitutes a reaction in some way to the teacher's intention to draw attention to some aspect of the student's initial utterance." They further divide uptake into two categories 'repair'- occurs when student corrects himself using the clue provided by the teacher and 'needsrepair'- occurs when a student needs additional guidance or explicit provision of the correct form.

A considerable number of research studies focuses on the effects of exposure to various feedback strategies. Although there is little agreement among researchers on the issue of which corrective moves produce the best results, it is possible to draw some conclusions from the research results presented below. Those in favour of more explicit techniques posit that it is essential for feedback to be explicit enough for learners to notice. In other words, when teachers are reluctant to tell students directly about their error, it often leads to confusion or causes ambiguities. All the same, most studies point to recasts - an implicit corrective move as being used most often in the classroom environment. In Lyster 
and Ranta's study (1997) recasts were counted as the most frequently used strategy, they accounted for $55 \%$ of all feedback moves. However, as it was mentioned before, the researchers questioned recasts as an efficient feedback tool, as they failed to lead students to self-generated repairs, thus they prevented uptake.

In contrast, Ellis (2009: 10) in his article states that according to Long (1996) recasts help to establish form-meaning connections and he advocates them as a strategy that "does not interfere with the flow of communication". In addition, Doughty and Varela (1998), cited in Kim (2004: 10), emphasized the usage of "corrective recasting that encourages attentional focus" in order to avoid ambiguity. What is more, in their study students were given an opportunity to repair the error before they were provided with targeted reformulation, which meant using more than one strategy to help students improve their language skills. Oliver's study (1995: 474), mentioned in the previous chapter, revealed that native speakers who provided correction used recasts when they reacted to singular errors (focus on form) but they used negotiation techniques when responding to multiple errors (to clarify the meaning). Similarly, Lyster (1998a) in his follow up investigation based on the data research from 1997, noticed that "Grammatical and phonological errors tended to invite recasts, whereas lexical errors tended to invite negotiation of form more often than recasts." (1998: 204). Moreover, some researchers (Mackey \& Philip 1998, Han 2002b, cited in Tatawy, 2002: 11) posit that recasts proved beneficial, provided that students reached their 'developmental readiness'. Han even points to four independent conditions: (1) individualized attention, (2) consistent linguistic focus, (3) learners developmental readiness and (4) intensity of the treatment that must be met in order for recast to reach desirable effect (Tawny 2002: 12). Interesting results were reached by Ammar and Spada (2006), who investigated the effects of prompts and recasts across different proficiency levels. They discovered that high-proficiency learners benefited equally from both prompts and recasts but low proficiency learners benefited more from prompts (2006: 571). Clearly, strategies should be applied with caution and with conviction in a predictable for students' manner. Teachers are strongly advised to use more than one technique depending on the type of error and students' proficiency level. Self-correction should be promoted with students who poses the necessary linguistic knowledge. In terms of recasts and other corrective implicit moves, they are welcomed provided that the teacher is aware of students' readiness to recognize linguistic features and is able to provide feedback without ambiguity.

It should be further noted that effective feedback strongly relies on teachers' understanding of the learner and their linguistic behavior, nevertheless, 
in the learning environment, there are variables that cannot be controlled. One such example is the shortage of time that a teacher has to face, especially when teaching in state schools. Other examples include working with uninterested and having learning difficulties students with whom all correction techniques seem to bring little improvement, or working in mixed ability class, where it is often challenging for teachers that some students need to be corrected significantly more. Further variables include students' unwelcome behaviour such as interruptions or performing peer-corrections without teacher's consent.

Last but not least, because corrective feedback is often perceived as a form of criticism, it is extremely important to express it tactfully and supportively so as to avoid student's humiliation. Teachers ought to be knowledgeable about how and when to provide feedback but also sensitive to students individual needs when providing one. Psycholinguistic variables such as learner attitude, aptitude and anxiety should also be accounted for when giving feedback. Throughout their careers, teachers receive various pedagogical advice on how to obtain best results with students. As it was mentioned before, it seems impossible to assume that there can be only one way of addressing students' errors, therefore, it is worth stating that Ellis (2009: 14) proposed ten general guidelines for using corrective feedback "It is a set of principles that teachers can reflect on when determining their own policy for corrective feedback". Interestingly, the first guideline acknowledges the importance of students' attitudes towards corrective feedback.

\section{Research findings}

Most research conducted regarding corrective feedback is rather teacher-oriented, still, teachers are strongly advised to correct following the cognitive and affective needs of the individual learner. The survey presented later in the article was designed with a modest objective of discovering students' perceptions and attitude towards correction and consists of three parts. In the first part, the learners had to reveal how they perceive teachers who deliver corrective feedback in the classroom. The second purpose of the survey was to validate or else the conviction that learners favour explicit immediate correction. The third part was devised to establish which feedback moves are most useful and effective from the learners' perspective.

The survey participants were 43 students of English, aged 13-17, enrolled in pre-intermediate and intermediate level courses at a private language school, all of whom had at least 3 years of training in learning English. During those years, the respondents have been taught by 3 to 6 different teachers which guaranteed 
a wide scope of observations regarding correction patterns in the classroom. Moreover, because they were students at private school, learning English in groups of 4 to 8 ensured that they were exposed to plenty of feedback moves.

In the first and second part of the survey the respondents were asked to read the instruction and react to 12 statements presented to them by marking their level of agreement or disagreement on a five-level format scale:

5 - Strongly agree

4 - Agree

3 - Neither agree nor disagree

2 - Disagree

1 - Strongly disagree

In the third part of the survey, eight different feedback techniques described in the previous chapter were introduced to students in the form of a dialog. Each dialog comprised an example of student's ill-formed utterance and the teacher's corresponding reaction to the student's error. The examples given were constructed in such a way that it was not difficult, even for a low intermediate student, to understand the nature of the mistake. Learners were asked to estimate how effective and useful they believe each presented technique is on a five-level scale. The survey, with the exception of student-teacher dialogs, was introduced to students in Polish, their native language, so as to avoid possible confusion or misinterpretation of the given tasks.

In the first question of the survey, students were asked if they were corrected each time they made an error and consequently, in the second part they were asked whether they expected the teacher always to correct them if an error occurred. Almost $84 \%$ of the respondents believe they are always corrected if they make an error and accordingly, 95\% of students expect to be corrected whenever they utter an ill-formed sentence. The results of the survey also confirmed that students in general favor immediate correction. When asked about the right time for providing correction, the majority of respondents both expected and observed that teachers give them immediate correction. $84 \%$ of students asked stated that teachers attended to their errors immediately after they heard them, and $76 \%$ of them also claimed that this was exactly what they needed. Interestingly though, few of the respondents resented immediate correction.

In the survey, students were further asked to reveal their attitude towards peer correction. A significant number of students agreed or strongly agreed that in the classroom teacher allows others to make the corrections (35\%), but an even greater number of students was indecisive on the issue (49\%). On the other hand, 
when asked about peer correction, $67 \%$ of students implied that they had nothing against it, provided it was done in a tactful manner.

On the issue of students reactions to correction offered by the teachers in the classroom, the respondents were asked to comment on whether they repeat the correct form after the correction, and whether they always agree with the teacher's comments regarding errors. Moreover, they were also asked to reveal their stance on the issue of explicitness of correction and the treatment of minor errors. The survey results revealed that only about $40 \%$ of the respondents admitted to repeating the correct form after the teacher, whereas about half of them (49\%) stated they did not do it. Also, a considerable number of students claimed they preferred the teacher to provide the correct form (58\%), and another 26\% remained indifferent about it. Furthermore, despite making minor errors, students still held high expectations towards teachers to correct their mistakes as $60 \%$ of the respondents expected correction at any rate, and only about $26 \%$ of students agreed with ignoring minor errors. On the whole, students accepted and appreciated teachers' comments on their errors, as $84 \%$ of them felt positive about it, and only one person showed uncertainty in that matter. In the survey, students further expressed their opinion towards the number of feedback strategies used and whether they expected their teacher to always explain the nature of the error. A considerable number of $77 \%$ of the respondents either disagreed with or stayed neutral about teachers using one corrective strategy in the classroom. Only $16 \%$ of the respondents were not interested in being given a clarification regarding their error.

In the third part of the survey, students were given the opportunity to state their preference towards different correction techniques teachers use in the classroom. What follows is a set of graphs presenting the level to which students either agree or disagree with a technique being useful and efficient in terms of correction and language learning. 

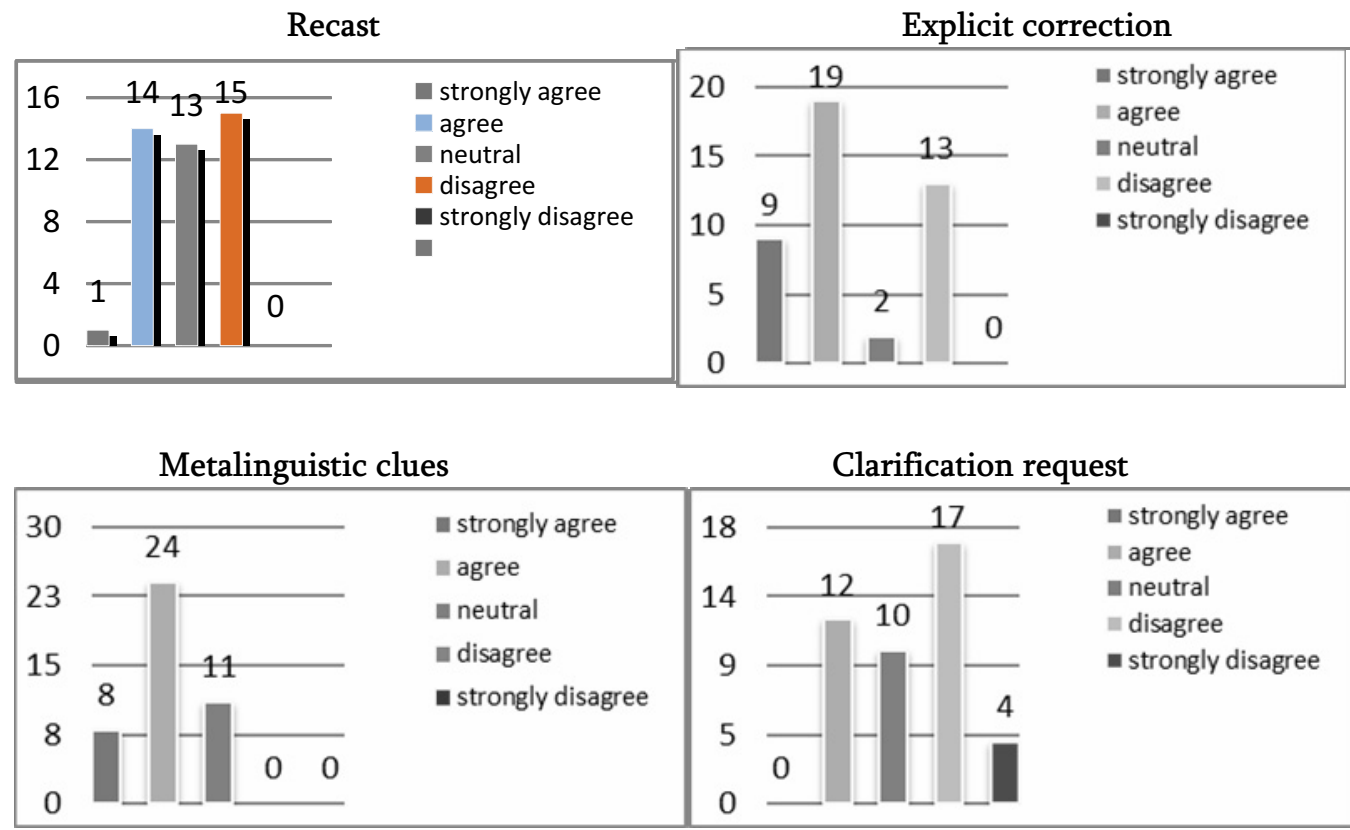

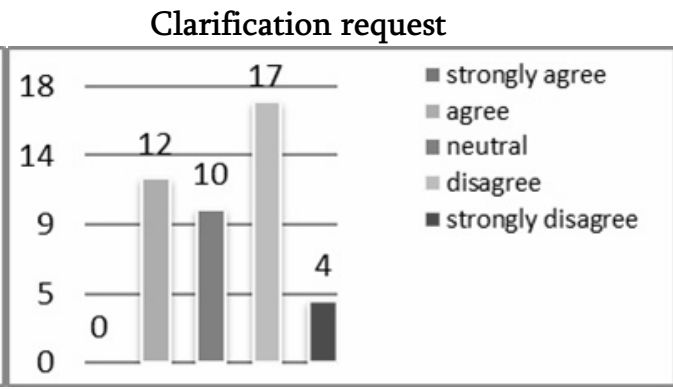

Elicitation

Repetition

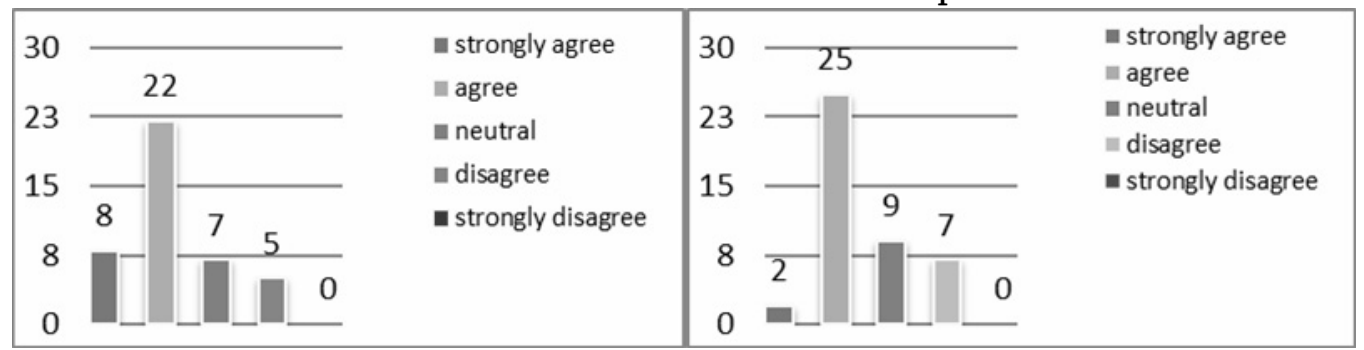

Translation

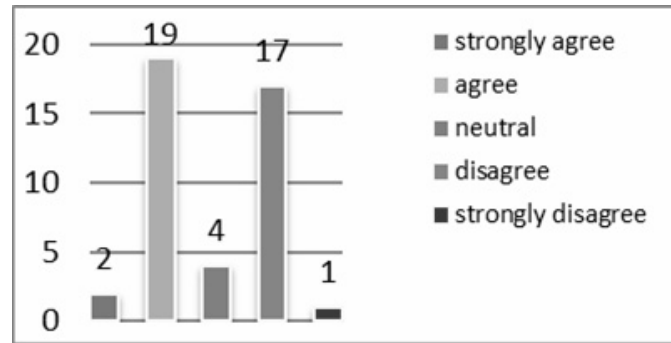

Paralinguistic signals

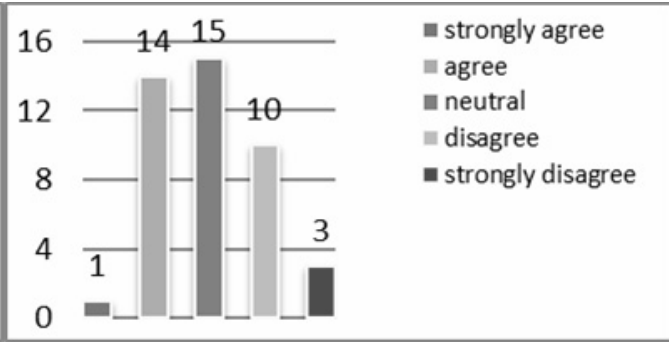

Summarizing, the results obtained point to recast as a strategy which has as many opponents as supporters, also $30 \%$ of students remained indifferent towards this 
implicit feedback move. Both explicit correction (65\%) and metalinguistic clues (74\%) proved popular with students, although only the latter one got no negative votes. Interestingly, clarification request, somewhat similar but less direct in comparison with metalinguistic move strategy, received a considerable number of negative comments (51\%). Furthermore, the research findings indicate a strong preference for elicitation and repetition among students as those feedback types were accepted by over $60 \%$ of the respondents, and additional $15-20 \%$ stated they neither agree nor disagree with it being useful. Translation technique met with mixed reviews. A fairly big number of students decided it was beneficial (49\%) but, at the same time, many students decided against it (42\%). Finally, about onethird of the respondents did not welcome paralinguistic signals as a preferable correction technique, still, the others were neutral or in favour of this feedback strategy.

First of all, it is interesting to notice that despite teachers claiming that not every error needs correction, students still see them as always attending to their errors. One explanation for that might be that students fail to classify some situations as those which require correction; hence they only notice and remember if they were explicitly told they made an error. The survey results also confirmed that students agreed with always being corrected as $95 \%$ of them agreed or strongly agreed that this is what they expect from their teacher. Interestingly, students believe that even their minor errors should be corrected. This might lead to the conclusion that from the learner's perspective, the ultimate objective in language learning is to acquire the ability to speak without errors.

Furthermore, correspondingly to Ancker's results (2000), it was revealed that most students favour immediate correction. It is worth mentioning though that 5 out of 6 students who declared that they disagree with immediate correction stated that they observe teachers giving instant corrections. Probably they feel that they are being interrupted if a teacher corrects them and maybe they would prefer to finish the utterance before being corrected. Regarding students' attitude toward peer correction in the classroom, about half of the respondents refrained from deciding whether teachers should allow it in the class and only $11 \%$ observed that teachers do not let others do the corrections. The survey results further revealed that a considerable number of students actually supports the idea of being corrected by their peers (67\%). This view contradicts Amador's results (2008). She discovered that $47.9 \%$ of the students asked implied that other peers should not correct them (Amador 2008: 21) the reason being that peer correction is unreliable and embarrassing (ibid.: 25). However, the respondents mentioned in this paper accepted peer correction on 
condition that it was done tactfully. Also, learning in small groups of 4 to 8 students probably creates a rather supportive learning environment, where students know each other well and therefore, are willing to accept corrections from peers.

In relation to the issue of what students do after being corrected and what they expect their teacher to do, it was revealed that students favor teachers themselves providing the correct form. This result is consistent with the fact that students showed a strong preference towards explicit correction techniques. Recasts were not as popular as explicit correction, although it should be noted that even explicit correction received some criticism from students. About 30\% of the respondents were hesitant to receive overt feedback. One explanation for it being that this technique can be seen as highly judgmental.

Also, students admitted to not repeating the correct form after the teacher as only $40 \%$ reacted to their error by repeating the teacher's reformulation. In the light of other research findings, such an outcome seems worrying as it was said elsewhere in this paper that lack of involvement on students part deters uptake; thus it does not support language development. The survey results further revealed that students showed considerable confidence in teachers giving feedback; however, this might be related to their proficiency level. It is possible that more advanced and confident learners could question some of the teachers' comments.

The analysis of the preference students have for various feedback moves suggests that there is no one corrective technique which they favor above others. It is also comforting that, to some extent, students agreed with the use of all the strategies they were presented with which proves that they welcome corrections and probably see them as a necessary aspect of language learning.

Overall, the respondents were the least skeptical about teachers using metalinguistic clues, elicitation and repetition. All three feedback strategies have been described as motivating students to 'self-repair' but if the first two are considered explicit, the latter one is rather implicit. What they all have in common is that, without revealing the correct form, the teacher clearly indicates to the student the source of the problem. It seems then, that despite the fact that many students want the teacher to provide the correct form, they also regard selfrepair techniques effective.

Clarification request strategy has not gained significant support from students, probably because it offers very little guidance in terms of the form and location of an error. In addition, this technique is often used to clarify the meaning of the ill-formed utterance and therefore, in most cases it proves to be challenging for low intermediate students. With respect to recasts, it seems 
that students are rather hesitant to receive this type of correction. Again, perhaps the reason for it is that it is a feedback move not informative enough for less advanced learners, hence it might pass unnoticed. The translation technique divided the respondents as half of them did not see it beneficial to have their error translated to their native language. Maybe they found it embarrassing or thought it would be uncomfortable to hear their error in their own language. On the other hand, some students are fond of being given explicit suggestions and straightforward examples seeing that it helps them remember the rules for correct forms. Probably the latter group was in favor of the translation technique. In the case of paralinguistic moves, students frequently presented a neutral opinion towards it. Surely, nonverbal indicators of an error are welcomed by learners but again on condition that they are easy enough to interpret.

\section{Conclusion}

Summing up, corrective feedback seems inherent in the process of gaining linguistic accuracy in language learning; therefore it is advisable for teachers to examine and reflect on their own instructional practices in order to find corrective moves which will be both beneficial for students and suitable for teachers. Moreover, even with respect to the theoretical views and empirical findings, it is also worth to acknowledge students' standpoint on the matter. First of all, teachers should always be aware of the fact that students expect correction at any rate, and that they view the teacher as an expert on the issue. Thus, if teachers refrain from correction, maybe it is worth explaining the rationale behind it. Moreover, teachers do not need to shy away from feedback and assessment but they have to make sure it is provided in a predictable for students manner, it is meaningful, and that it caters for students' individual needs. In addition, the above survey results suggest that in a well-controlled learning environment teachers can allow peer correction. Possibly they can even design activities in which peers correct each other as long as they present the necessary knowledge. It is further advisable for teachers to remember that students welcome all indicators of mistakes, however, in order for prompts to be successful, they are supposed to be neither too subtle nor ambiguous, especially with low intermediate students. The intention of a corrective move is to give clarification rather than confusion, which should mean providing appropriate cues for the learners to selfrepair.

From this perspective, feedback moves such as metalinguistic clues, elicitation and repetition seem to be the right move as students showed a strong 
preference towards those feedback strategies in the survey. Choosing them should be especially encouraging since according to Panova and Lyster, those techniques show the highest rates of learner uptake (1992: 586). Last but not least, teachers ought to remember that even the most persistent and well-adjusted correction does not always guarantee success. Recurring corrections of the same error will happen and after all, students can only absorb a limited amount of feedback information at one meeting. Nevertheless, students agree to being corrected, and they see it as a necessary and useful form of teacher-student communication and they trust teachers to help them improve their language accuracy.

In general, students' attitude towards correction revealed in the survey is consistent with many research studies on error correction. It was discovered that students welcome corrections, and often expect to be explicitly told either directly or by means of clear clues what the correct form is. Consequently, it is advisable to promote students' autonomous learning by providing them with opportunities to self-repair.

\section{Bibliography}

Amador, A. Y. (2008). "Learner attitudes toward error correction in a beginners English class". [In:] Revista Comunicacion Volumen 17 (1), 18-28.

Ammar, A., Spada, N. (2006). "One size fits all?: Recasts, prompts, and L2 learning”. [In:] Studies in Second Language Acquisition 28,543-574.

Ancker, W. (2000). "Errors and Corrective Feedback: Updated Theory and Classroom Practice". [In:] English Teaching Forum 38 (4), 20-24.

Carroll, S., Swain, M. (1992). "The Role of Feedback in adult second language acquisition: Error correction and morphological generalizations". [In:] Applied Psycholinguistics 13, 173-198.

Chaudron, C. (1977). "A descriptive model of discourse in the corrective treatment of learners' errors". [In:] Language Learning 27, 29-46.

Cepni, S. B. (2016). A replication study: Oral corrective feedback on L2 writing; two approaches compared. Procedia Social and Behavioral Sciences, 232, 520-528. [doi.org/10.1016/j.sbspro.2016.10.072].

Chomsky, N. (1975). Reflections on language. New York: Pantheon.

Dignen, B. (2014). Five reasons why feedback may be the most important skills. Available at: http://www.cambridge.org/elt/blog/2014/03/fivereasons-feedback-may-important -skill/ (accessed on 6 December 2014).

Dudley-Evans, T., \& St John, M. J. (1998). Developments in ESP. A Multi-disciplinary Approach. Cambridge: Cambridge University Press.

Ellis, R. (2009). "Corrective Feedback and Teacher Development". [In:] L2 Journal 1(1): 3-18. 
Hargreaves, E., McCallum B., Gipps, C. (2000). "Feedback for young people's learning”. [In:] Suzan Askew (eds.). Feedback for learning. London-New York: Routledge, 21-31.

Kim, J. H. (2004). "Issues of corrective feedback in second language acquisition." Working Papers in TESOL \& Applied Linguistics 4 (2): 1-24.

Krashen, S. D. (1982). Principles and Practice in Second Language Acquisition. New York: Pergamon Institute of English.

Leeman, J. (2007). "Feedback in L2 learning: Responding to errors during practice". [In:] Robert M. DeKeyser (Eds.). Practice in a second language. New York: Cambridge University Press, 111-131.

Lightbown, P. M., Spada, N. (1990). "Focus-on-Form and Corrective Feedback in Communicative Language Teaching: Effects on second language acquisition". Studies in second Language Acquisition 12, 429-448.

Lyster, R. (1998a). "Negotiation of Form, Recasts, and Explicit Correction in Relation to Error Types and Learner Repair in Immersion Classrooms". Language Learning 48, 183-218.

Lyster, R., Ranta, L. (1997). "Corrective Feedback and Learner Uptake. Negotiation of Form in Communicative Classrooms”. Studies in Language Acquisition 19, 37-66.

Lyster, R., Ranta, L. (2007). “A cognitive approach to improving immersion students' oral language abilities: The Awareness-Practice- Feedback sequence”. [In:] Robert M. DeKeyser (Eds.). Practice in a second language. New York: Cambridge University Press, 141-161.

Mudra, H. (2014). The utilization of authentic materials in Indonesian EFL contexts: an exploratory study on learners' perceptions. International Journal of English Language \& Translation Studies, 2(2), 197-210. Available at www.eltsjournal.org (accessed on 8 December 2014).

Norris, J. M., Ortega, L. (2000). "Effectiveness of L2 Instruction: A Research Synthesis and Quantitative Meta-analysis". Language Learning 50, 417-528.

Oliver, R. (1995). "Negative Feedback in Child NS-NNS Conversation". Studies in Second Language Acquisition 17, 459-481.

Panova, I., Lyster, R. (2002). "Patterns of corrective feedback and uptake in an adult ESL classroom”. TESOL Quarterly36, 573-595.

Rollinson, P. (2005) 'Using peer feedback in the ESL writing class', ELT Journal, 59(1), 23-30. [doi: 10.1093/elt/cci003].

Schwartz, B. D. (1993). "On explicit and negative data effecting and affecting competence and linguistic behaviour". Studies in Second Language Acquisition 15, 147-163.

El Tatawy, M. (2002). "Corrective Feedback in Second Language Acquisition”. Working Papers in TESOL \& Applied Linguistics 2, 2.

Ur, P. (1996). A Course in Language Teaching: Practice of theory. Cambridge: Cambridge University Press.

Wright, Tony (2005). Classroom management in language education. Basingstoke, UK: Palgrave Macmillan. 
